\title{
Чем сложнее аналитическая задача, тем ярче проявляются уникальные характеристики наших приборов
}

Рассказывает Вячеслав Борисович Артаев, технический директор LECO Separation Science

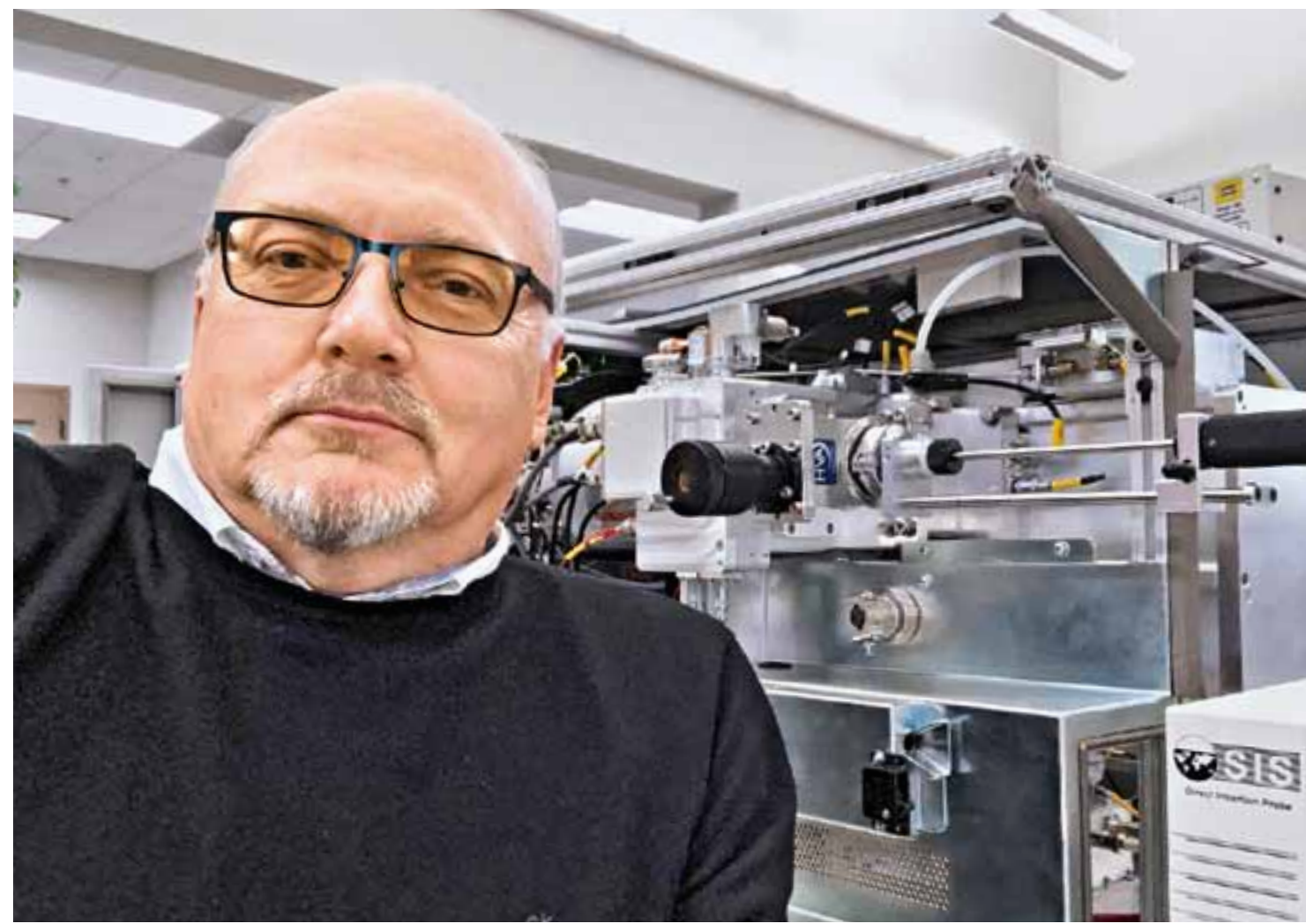

Корпорация LECO широко известна во всем мире как разработчик и производитель аналитического оборудования высокого класса. Одно из направлений ее деятельности - LECO Separation Science - связано с развитием и совершенствованием техники хромато-масс-спектрометрии на основе времяпролетных масс-спектрометров (ВПМС) в сочетании с газовыми хроматографами (ГX). Технический директор направления Вячеслав Борисович Артаев рассказал о работе подразделения, о новых продуктах, их особенностях и преимуществах.

В каком сегменте глобального рынка оборудования для масс-спектрометрии корпорация LECO чувствует себя наиболее уверенно?

Мы сфокусированы на разработке и производстве приборов для двумерной газовой хроматографии и на времяпролетных масс-спектрометрах
(ГХ×ГX/MC). Это наша ниша, в ней LECO - ведущая компания на глобальном рынке оборудования для масс-спектрометрии. Двумерная хроматография у исследователей во всем мире сегодня ассоциируется с нашим брендом. По характеристикам и возможностям применения приборов мы опережаем крупных производителей, работающих в этом сегменте. 
Как территориально распределяются продажи оборудования, которое разрабатывает LECO Separation Science?

Мы не видим никаких особых перекосов в каком-то из регионов. Продажи наших продуктов, не только масс-спектрометров, распределяются довольно ровно: 30\% приходится на США, 30\% на Европу, в том числе Россию, и еще $30 \%$ - это Азия. В последнее время подтягивается Южная

Америка, некий всплеск активности потенциальных заказчиков начинается и там.

В каких областях востребовано оборудование, разработанное специалистами вашего отделения?

Отделение LECO Separation Science занимается разработкой и выпуском приборов для очень широкого круга задач, все их трудно перечислить. Практически в любых научных и технологических отраслях, где речь идет о необходимости определения химического состава очень сложных смесей летучих и полулетучих веществ, наши приборы находят применение. Это исследования в биологии, растениеводстве, фармацевтике и медицине, анализ окружающей среды, воды, различных напитков, продуктов питания и их исходных ингредиентов, а также кормов для домашних и сельскохозяйственных животных.

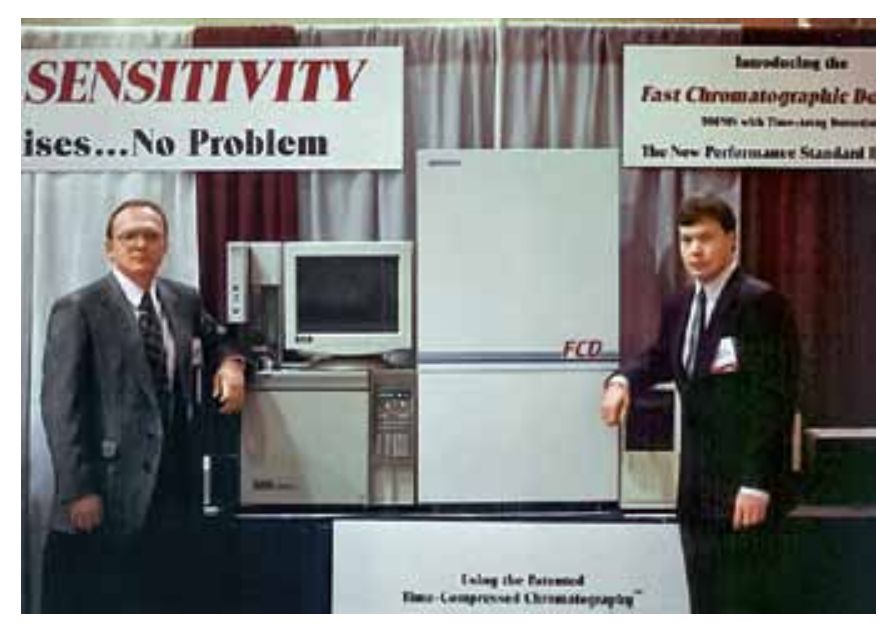

В. Б. Артаев и К. Макнитт: презентация ГХ/МС для скоростного анализа на основе ВПМС (1995 год, Pittcon)
Те, у кого есть кошки или собаки, знают, что они очень привередливы. Поэтому производителям корма очень важно обеспечить постоянство состава и качества ингредиентов. С помощью наших приборов они могут его поддерживать на высочайшем уровне.

Нефти - очень сложные химические смеси, поскольку в них содержатся десятки тысяч различных компонентов. Разработанные

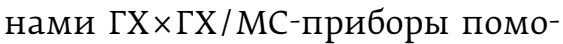
гают успешно справляться с анализом различных видов нефти и топлива для оптимизации методов переработки, геохимических исследований, при определении добавок и примесей, для идентификации источников разлива и т.д.

Наши приборы используются также и для медицинских исследований, например, связанных с изучением метаболической реакции в сыворотке крови людей, зараженных SARS-CoV-2. Работа на эту тему была опубликована в ноябре прошлого года группой итальянских ученых из медицинского центра университета Piemonte Orientale.

Даже в археологических исследованиях использование ГХ ×ГХ/MC для анализа артефактов помогает получить уникальные данные. Результатам одного из них посвящена принятая к публикации совместная работа по анализу участков древнеегипетской мумии, проведенная группой профессора А. Т. Лебедева из МГУ им. М. В. Ломоносова (кстати, основателя

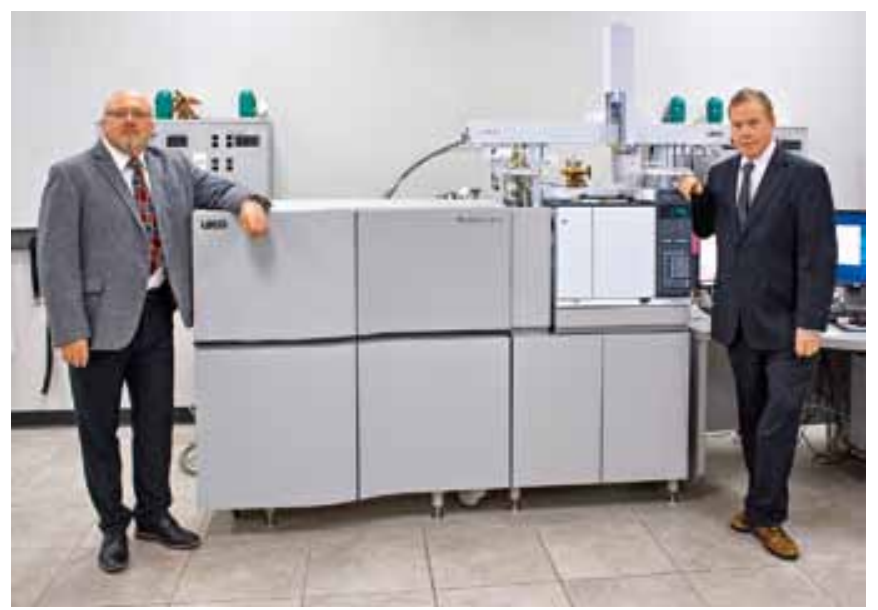

В. Б. Артаев и К. Макнитт. Новейшая модель ГХ/МС с ВПМС высокого разрешения и двумерной газовой хроматографией Pegasus GC-HRT + 4D 
Всероссийского масс-спектрометрического общества) и сотрудниками Государственного музея изобразительных искусств им. А. С. Пушкина.

\section{На какие тренды развития современного ана- литического оборудования вы ориентируетесь при разработке приборов?}

Мы видим, что в современных условиях массспектрометрией занимаются уже не только массспектрометристы, но и люди других профессий: технологи, врачи, биологи и др. Они хотят сами работать на этих приборах, чтобы получать необходимую им информацию. Для этого нужны масс-спектрометры, которыми просто управлять и настраивать на нужный режим для получения объективных результатов. Я считаю, что сегодня одно из самых главных направлений развития - разработка приборов, с одной стороны, user-friendly, то есть легко подстраивающихся под запросы пользователей, а с другой - устойчивых к ошибочным действиям неопытных операторов.

И еще один тренд связан с программным обеспечением. Сейчас очень многих потенциальных исследователей интересует не то, как масс-спектрометр работает, а какую информацию и в каком виде он выдает и насколько легко и удобно с полученными данными работать. Подавляющее большинство - 99\% наших пользователей - сразу хочет получать данные о качественном и количественном составе образца и ответы на вопросы: что и как поменяется при изменении каких-либо условий, в чем разница? Такие ответы должны быть получены с помощью удобного и быстрого программного обеспечения.

Эти два тренда - упрощение в управлении оборудованием и совершенствование программного обеспечения - кажутся мне наиболее перспективными для расширения рынка.

\section{Расскажите о новых продуктах и технологиях, которые в них используются.}

Минувший 2020 год был непростым, но, несмотря на всем понятные трудности, наш отдел научных исследований и новых разработок подготовил к выпуску несколько новых продуктов, связанных с линейкой времяпролетных масс-спектрометров в сочетании с двумерной газовой хроматографией. Расскажу о двух новых разработках, которые считаю наиболее интересными и перспективными.

Первая - это новый источник ионов для нашего флагманского прибора Pegasus GC-HRT, который выпускается с 2011 года. Примерно каждые два-три года мы существенно улучшаем его характеристики и расширяем возможности применения. Таким образом, уже сейчас Pegasus GC-HRT обладает уникальными аналитическими характеристиками: высокой разрешающей способностью; высокоточным определением массы ионов; высокой скоростью записи

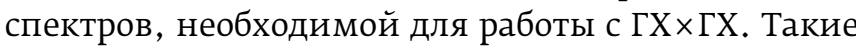
характеристики прибора позволяют с высокой уверенностью идентифицировать неизвестные химические вещества в сложных смесях.

Известным аналитическим приемом для улучшения надежности идентификации является применение различных методов ионизации. Дополнительная информация, извлеченная из разных типов спектров, используется для подтверждения или опровержения предполагаемой идентификации компонентов смеси. Обычно применение разных методов ионизации требует перестановки соответствующих источников ионов, что не всегда удобно, поскольку она производится вручную и может вызвать изменение хроматографических условий.

Наш новый уникальный продукт, который мы разрабатывали несколько лет - MMS (multi-mode source - многорежкимый ионный источник), позволяет в одном источнике ионов при оптимальных условиях получать разные виды масс-спектров: электронной ионизации, химической ионизации с образованием положительных и отрицательных ионов. Таким образом, один и тот же образец можно проанализировать разными методами ионизации, меняя только способы анализа в автоматическом режиме при одних и тех же хроматографических условиях. Такой подход позволяет всесторонне исследовать образец на основе многофакторной спектральной и хроматографической информации и значительно улучшить надежность определения химического состава сложных смесей. Сегодня Pegasus GC-HRT в его различных модификациях - универсальный прибор для целевого и нецелевого анализа сложных смесей летучих и полулетучих веществ, а с добавлением многорежимного 
источника ионов MMS его возможности уверенной идентификации становятся еще шире. Мы надеемся, что многие наши сегодняшние и будущие пользователи заинтересуются новым инструментом.

Вторая разработка наших специалистов - новый программный продукт ChromaTOF-Tile. Эта универсальная компьютерная программа предназначена для сравнения между собой образцов на основе данных анализа, полученных методами двумерной хромато-масс-спектрометрии на любом из приборов фирмы LECO. Хорошо известно, что анализ методами двумерной хроматографии в сочетании с массспектрометрией позволяет детектировать большое количество сигналов, многие из которых невозможно зарегистрировать другими методами. Но полученное большое количество информации вызывает подчас трудности с обработкой результатов особенно при необходимости сравнения больших массивов данных. Поэтому мы разработали ChromaTOF-Tile - абсолютно новую программу, с помощью которой можно выявить различия в химических составах разных классов образцов. И, что особенно важно, этот программный продукт справляется с непростой задачей обработки десятков гигабайт информации в кратчайшие сроки. Благодаря интеллектуальным методам редуцирования информации и другим инновационным решениям, время обработки сократилось с десятков часов до нескольких минут. Мы надеемся, что инновационное программное обеспечение значительно расширит возможности для пользователей наших приборов и позволит им решать новые аналитические задачи.

\section{Каковы преимущества и осо- бенности продукции компа- нии по сравнению с конку- рентами?}

В основе наших продуктов лежит несколько ключевых технологий, позволяющих нашим приборам выделяться на фоне конкурентов, которых достаточно в области газовой хромато-массспектрометрии. Различные типы уникальных времяпролетных масс-спектрометров мы разрабатываем на протяжении почти 25 лет. Изначально все приборы создавались внутри нашей организации или в тесном сотрудничестве с ведущими учеными в этой области. Такой подход и сейчас позволяет нам уверенно развивать и улучшать технические характеристики оборудования, строить долгосрочные планы разработки новых инструментов с уникальными характеристиками. Наши системы регистрации данных - это основа успешного применения ГХ/MC на основе времяпролетных массспектрометров, поскольку высокая скорость и огромное количество генерируемой информации требуют регистрировать и передавать всю получаемую с прибора информацию без потерь. Успешно решив эту задачу, мы смогли в полную силу использовать все преимущества времяпролетных масс-анализаторов: скорость регистрации, широкий массовый диапазон в спектрах, высокие разрешение и чувствительность, широкий динамический диапазон. И все это - одновременно в каждый момент регистрации аналитического сигнала. Таких возможностей нет ни у одного нашего конкурента.

Еще одно преимущество LECO Separation Science перед другими производителями ГХ/MC - наш фокус на технологиях для двумерной хроматографии. Как я уже говорил - это наша специализация, мы более 20 лет работаем в этой области, являясь во многом пионерами. Приборы LECO

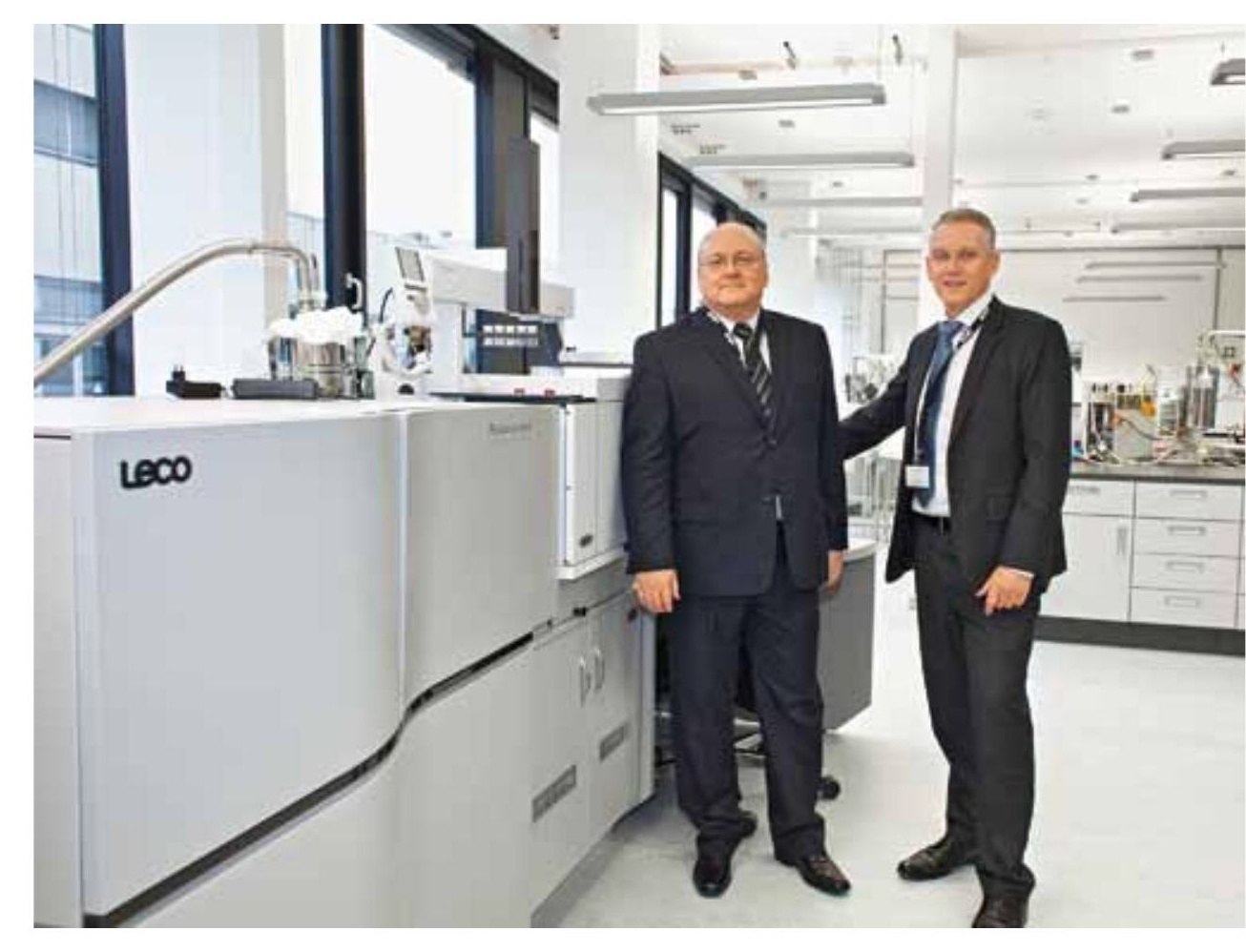

Oткрытие центра LECO European Application and Technology Center (EATC) в Берлине. В. Б. Артаев и Р. Лешер, вице-президент LECO Corporation, 2015 год 


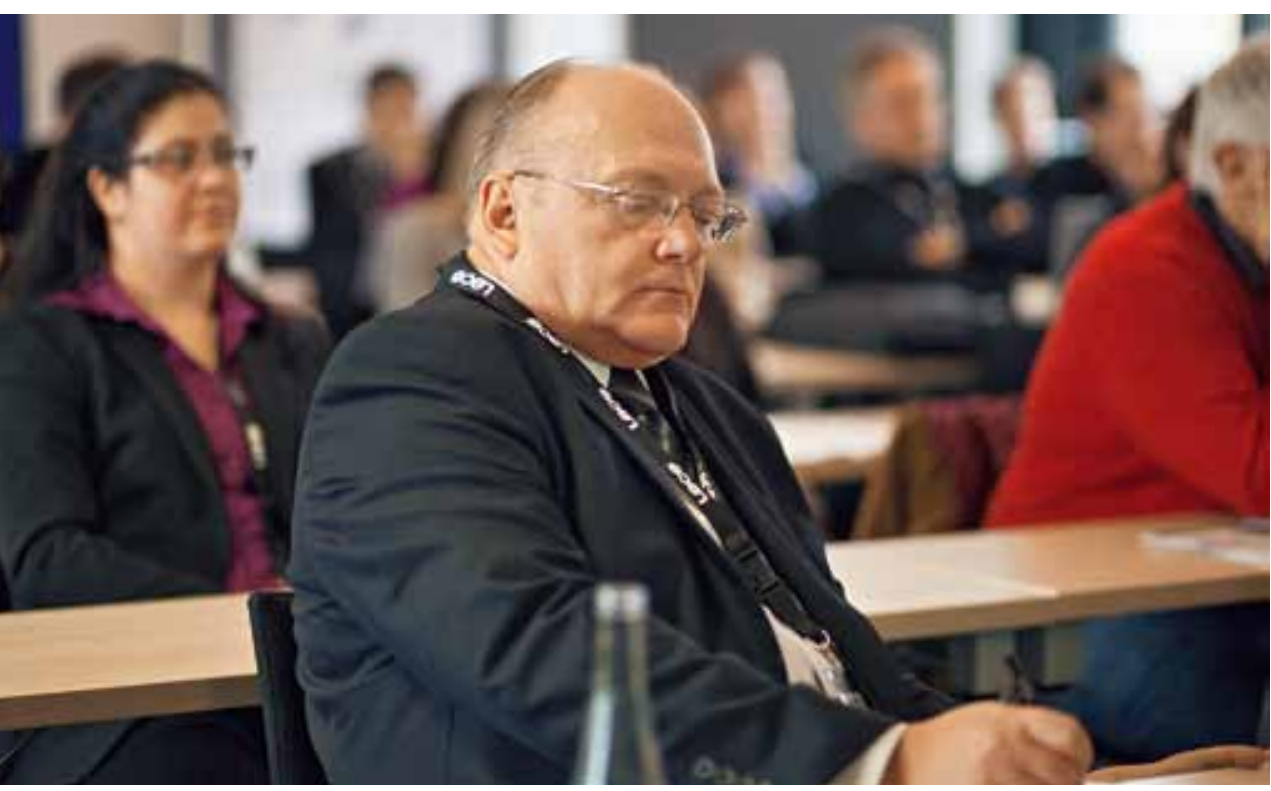

В. Б. Артаев в ЕАТС на конференции пользователей хромато-массспектрометров LECO, 2015 год

Separation Science специально сконструированы для работы с двумерной газовой хроматографией. Начиная с уникального термомодулятора до времяпролетного масс-спектрометра и программного обеспечения для визуализации и обработки дан ${ }^{-}$ ных - все полностью интегрировано и оптимизировано и работает как единое целое. Пользователи наших приборов получают готовый к работе инструмент, не требующий установки дополнительных компонентов от различных производителей и последующей их интеграции друг с другом.

Чем сложнее аналитическая задача, тем ярче проявляются уникальные характеристики наших приборов. Так, для анализа сложных химических смесей необходимы высокоэффективное хроматографическое разделение, высокая скорость и широкий динамический диапазон регистрации спектров, большой интервал измеряемых масс. Кроме того, программное обеспечение позволяет в разумное время обрабатывать огромные массивы информации и предоставлять ее пользователям. И все это доступно в различных конфигурациях линейки приборов - от настольного суперчувствительного Pegasus BT 4D до высокоразрешающего Pegasus HRT 4D.

\section{Что дает вам основание часто повторять по отно- шению к вашим приборам определение "уникальный»?}

Я использую слово "уникальный", чтобы подчеркнуть, что аналогов этих приборов или программного обеспечения у других производителей просто нет. Довольно часто для решения какой-то технической задачи в области массспектрометрии нужно разработать нечто уникальное. К примеру, сердцем нашего времяпролетного масс-спектрометра с высоким разрешением является уникальный времяпролетный масс-анализатор. Благодаря ему весь прибор тоже становится уникальным. Довольно долго проблема повышения разрешающей способности времяпролетных масс-спектрометров была барьером для развития их применения, пока в 70-е годы профессор Б. А. Мамырин не разработал схему прибора, известного во всем мире как "рефлектрон Мамырина". С тех пор улучшение разрешения времяпролетных масс-спектрометров достигалось путем увеличения их размеров. В результате они становились все больше и больше, потому что при этом увеличивалось время пролета, а следовательно, и их разрешение.

Мы с исследователями из компании Mass Spectrometry Consulting, возглавляемой д.ф.- м.н. А.Н. Веренчиковым, пошли по другому пути. Взяв за основу разработки А.Н. Веренчикова - принцип планарных бессеточных зеркал и принцип временной и пространственной фокусировки в периодических линзах, сделали времяпролетный масс-спектрометр многоотражательным. Совместными усилиями нам удалось найти техническое решение, позволяющее набрать необходимую длину пролета ионов в сравнительно маленьком по размеру анализаторе.

В этом смысле уникальность для LECO Separation Science - это то, о чем нельзя было заранее прочесть ни в учебнике, ни в статьях. Эти устройства придумали и внедрили или мы сами, или совместно с партнерами. Все наши инновации, естественно, 
патентуются, а наличие патента - это один из признаков уникальности.

Да и в целом, масс-спектрометрия как индустрия предполагает инновации. Приезжая на крупнейшую в этой области ежегодную международную конференцию Американского масс-спектрометрического общества, ученые, инженеры, исследователи со всего мира ожидают, что им представят что-то новое. И надо признать: такое давление со стороны пользователей заставляет разработчиков и производителей приборов создавать уникальное оборудование для решения новых задач.

\section{I А сколько у вас патентов?}

У меня с десяток патентов, наверное, а у отделения явно больше. Хотя речь идет не о сотнях, поскольку над каждым ведется очень сложная работа с привлечением патентных юристов. Защищать свои разработки - это тоже очень важная часть нашей работы в LECO Separation Science, но патенты - это не самоцель. Часто разработка патентуется для того, чтобы кто-то другой нас не опередил. На каждом нашем приборе - сзади, на крышке - указаны все патенты, которые в нем используются.

\section{Вы - соавтор ряда науч- ных статей. Как помогает в работе сотрудничество с научными коллективами?}

Сотрудничество с научными коллективами - это обязательная часть нашей деятельности. Мы опираемся на мнение исследователей при разработке новых устройств, аналитических методов и программных алгоритмов. Привлекаем ученых на разных этапах создания приборов: от лицензирования уже создан ных идей и решений до работы над идеями, которые не кажутся сейчас актуальными, но расширяют круг наших знаний и могут быть когда-либо использованы в наших новых разработках. Сотрудничаем мы с научными группами по применению наших серийных приборов и, что еще более важно, находящихся в разработке прототипов. Эта часть совместной работы очень полезна и показательна. Мы передаем новые разработки в производство только после того, как на них поработали исследователи и высказали свои мнения и пожелания. Мы понимаем, что на рынке успешным может быть только тот прибор, который позволяет получать новые знания.

В процессе разработки новых устройств мы, как правило, используем стандарты химических соединений, чтобы подтвердить заявленные характеристики. Но всегда самый лучший тест - это анализ реальных образцов, полученных от научных групп, с которыми мы сотрудничаем. При этом понятно, что успешно справиться с таким анализом и интерпретировать его результаты могут только те, кто знает все об анализируемом образце, то есть сами ученые, разумеется, с нашим участием как разработчиков оборудования и программ обработки данных. И горящие глаза наших коллег-ученых при получении уникальных результатов являются для нас самым лучшим индикатором успешности проекта.

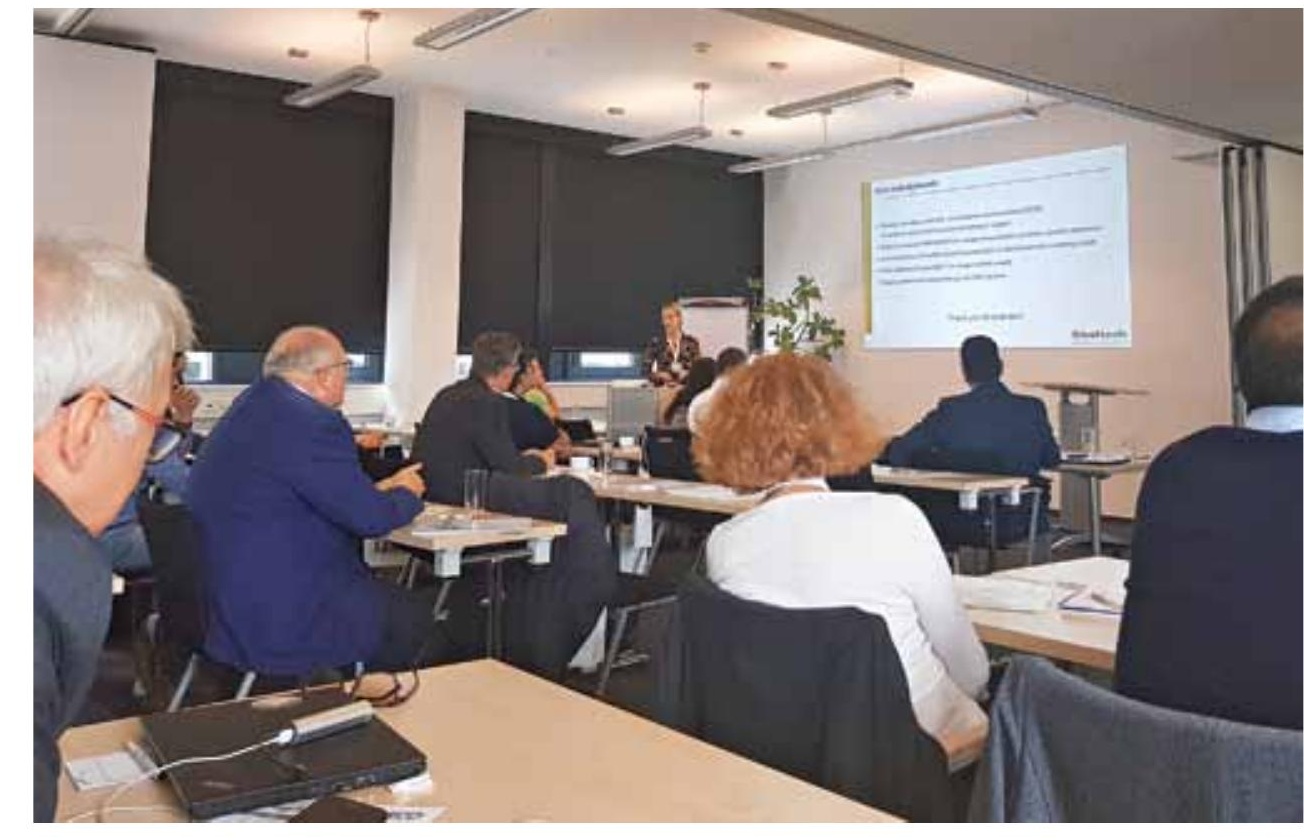

Европейский симпозиум LECO. Сотрудница Сколковского института науки и технологий Е.А.Леушина делает доклад по применению хромато-массспектрометра Pegasus 4D GC × GC-TOFMS для решения задач органической геохимии, 2019 год 


\section{Как LECO Separation Science сотрудничает с университетами, американскими и россий- скими?}

Поскольку в США большинство научных исследований проводится в университетах, то на наших приборах часто работают аспиранты и молодые преподаватели, участвующие в проектах. Они используют в своей работе современное оборудование, и всегда при обращении к нам получают поддержку, например детальное разъяснение функций того или иного прибора либо программы.

Что касается университетов российских, то я уже упомянул профессора кафедры органической химии химического факультета МГУ А. Т. Лебедева. И он, и его сотрудники приезжают к нам в Мичиган. Когда-то они были аспирантами, теперь стали молодыми учеными. Так что никаких отдельных обучающих проектов у нашего отделения нет: знания российские коллеги приобретают во время совместной работы.

Кроме того, наш времяпролетный масс-спектрометр Pegasus Classic установлен в Сколковском институте науки и технологий. Там молодые научные сотрудники и аспиранты, с которыми мы всегда рады общаться, используют его для геохимических исследований.

Лично мне гораздо удобнее работать с учеными из России. Между нами нет никаких барьеров: ни языковых, ни культурных, ни организационных. Мы понимаем друг друга, знаем, как лучше организовать совместную работу, и не стесняемся быть откровенными.

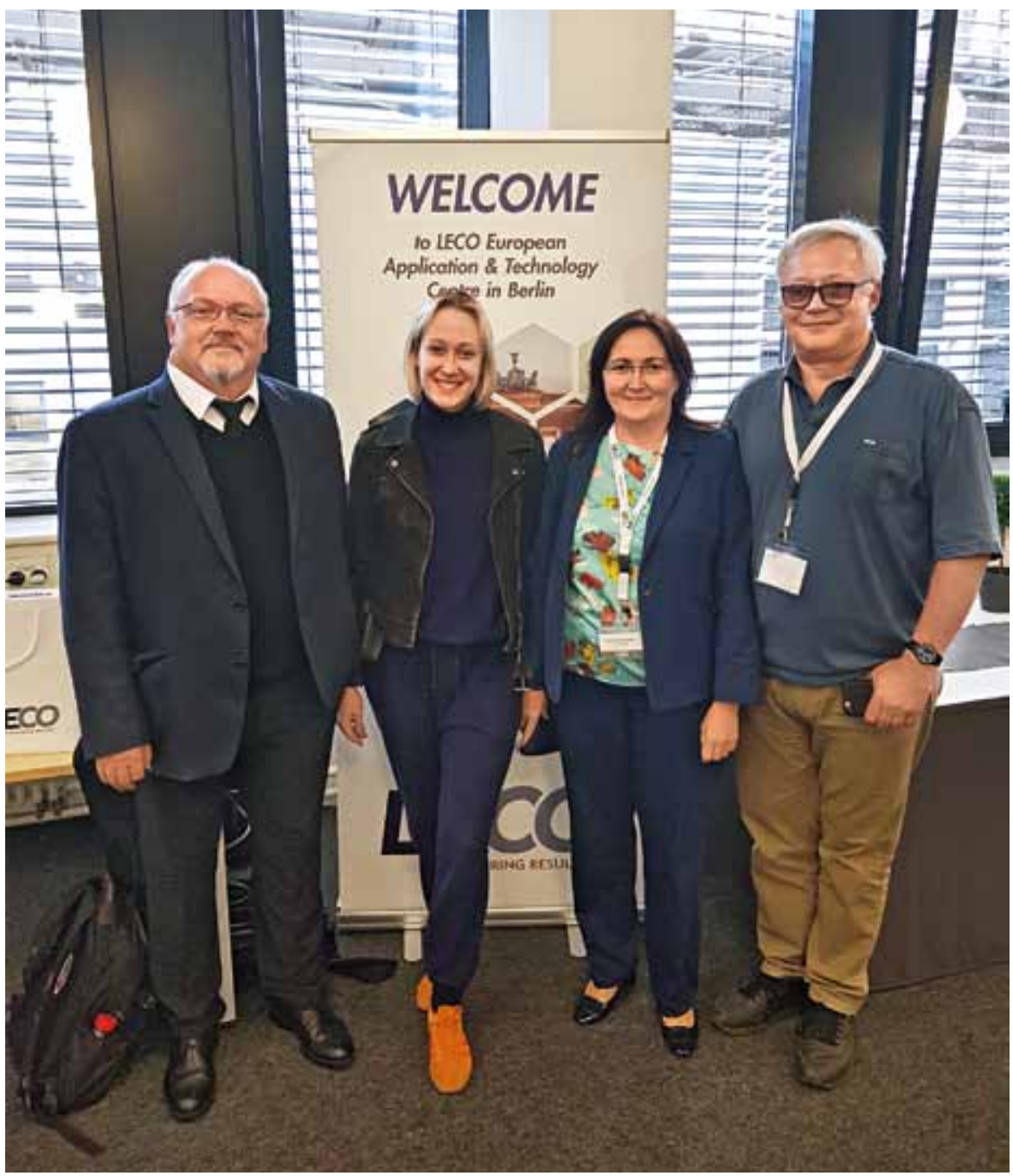

В. Б. Артаев, Е.А. Леушина (Сколковский институт науки и технологий), Г. М. Шайдулиина (представительство LECO Corporation в РФ и странах СНГ), М. Ю. Спасенных (директор Центра добычи углеводородов Сколковского института науки и технологий), 2019 год

\section{Каким был ваш путь в кор- порацию LECO?}

В 90-е годы достаточно широко развивалось сотрудничество с зарубежными компаниями. В 1992 году меня, в то время преподавателя и научного сотрудника МИФИ в группе профессора А. А. Сысоева, пригласили на пару месяцев в маленькую инженерную компанию из штата Мичиган для участия в одном проекте. Я поехал туда на два месяца во время своего летнего отпуска. Все это время занимался там только расчетами, идеями, обработкой, проектированием (все необходимые условия, включая оборудование, для этого были или доставлялись в течение недели) и до возвращения в Москву сделал успешно работающий прототип. А уже в начале 1993 года мне позвонили из этой компании, сообщили, что получили грант под эту разработку, и предложили переехать в США.

За два года мы довели разработку до готового продукта, а вскоре после этого компанию, в которой мы работали, 
приобрела LECO Corporation. Так что в прошлом году исполнилось 25 лет со дня моего перехода в эту корпорацию.

\section{В прошлом году 25 лет исполнилось предста- вительству LECO Corporation в России и стра- нах СНГ. Какие успехи достигнуты за это время?}

За 85-летнюю историю корпорация LECO открыла более 40 представительств с широкой сетью дистрибьюторов по всему миру, в том числе в 1994 году и в России. ЗАО «ЛЕКО ЦЕНТР-М» является экскЛюзивным представителем корпорации на территории России и в странах СНГ, организует поставку приборов и оригинальных расходных материалов, осуществляет инсталляцию и сервисное обслуживание оборудования, обеспечивает техническую поддержку пользователей и соблюдение гарантийных обязательств. Если в самом начале основными клиентами в России были предприятия черной и цветной металлургии, пищевой промышленности, горнорудной и особенно угледобывающей промышленности, то в последние годы заметно выросла доля научных организаций. Для ученых представляют интерес не только приборы из нашей основной линейки (элементные анализаторы, спектрометры тлеющего разряда, калориметры, термогравиметрические анализаторы), но и времяпролетные хромато-масс-спектрометры. Подразделение LECO Separation Science в российском представительстве неуклонно растет, расширяется штат сервисных инженеров, имеющих необходимую подготовку для запуска и технического обслуживания хроматомасс-спектрометров LECO в России без привлечения специалистов из других стран. Это оказалось особенно важным в условиях ограничения передвижений из-за пандемии коронавируса.

\section{Продукция компании - высокотехнологичная и требует квалифицированных специалистов для введения в эксплуатацию оборудования, его обслуживания и ремонта. Как работает сервисная служба?}

В прошлом году наша сервисная служба в сотрудничестве с другими отделениями компании запустила проект дистанционного обучения LECO Learn, дополнив таким образом традиционные методы обучения и сервисного обслуживания. Это серия коротких видеоинструкций на YouTube к нашему оборудованию, показывающих, как включить прибор, как получить с него данные, как установить некие параметры и т. д. И мы видим, что все больше и больше наших пользователей обращаются к этим материалам и очень позитивно откликаются на такие новые возможности получения необходимых навыков.

Добавлю, что все наши приборы можно подключать к Интернету, так что сервисная служба может проводить диагностику дистанционно.

\section{Расскажите, пожалуйста, о ваших ближайших и перспективных планах}

В ближайших наших планах - расширение линейки типов ГХхГХ-модуляторов, применяемых в наших приборах. В наиболее эффективных сейчас типах модуляторов, которые мы используем, термических, применяются потоки холодного и горячего газа для заморозки и ре-инжектировании аналитов во вторичную хроматографическую колонку. Для максимальной эффективности заморозки необходимы низкие температуры, которые можно получать с помощью жидкого азота или при использовании иммерсионных холодильников в сочетании с компрессором. Такой метод дает наилучшие результаты. А для тех пользователей, которым требуется режим двумерной хроматографии не так часто, но при этом они хотели бы иногда его использовать без дооснащения хроматомасс-спектрометра иммерсионным холодильником или системой подачи жидкого азота, подходит опция с потоковым модулятором. Вот почему мы ведем работы по разработке дополнительных методов модуляции, как термических, так и основанных на модуляции потоками газа для бо́льшего удобства наших клиентов. Мы также работаем над различными аспектами улучшения наших массспектрометров. Ну и программное обеспечение находится в постоянном развитии, работа над новыми продуктами в этой сфере продолжается.

\section{I Спасибо за интересный рассказ.}

С В.Б.Артаевым беседовали А.Е.Крылова и В.В. Родченкова. 